\title{
Crystal sedimentation and stone formation
}

\author{
Johannes Markus Baumann · Beat Affolter • \\ Rolf Meyer
}

Received: 27 May 2009/Accepted: 4 November 2009/Published online: 8 December 2009

(C) The Author(s) 2009. This article is published with open access at Springerlink.com

\begin{abstract}
Mechanisms of crystal collision being the first step of aggregation (AGN) were analyzed for calcium oxalate monohydrate (COM) directly produced in urine. $\mathrm{COM}$ was produced by oxalate titration in urine of seven healthy men, in solutions of urinary macromolecules and in buffered distilled water (control). Crystal formation and sedimentation were followed by a spectrophotometer and analyzed by scanning electron microscopy. Viscosity of urine was measured at $37^{\circ} \mathrm{C}$. From results, sedimentation rate $\left(v_{\mathrm{S}}\right)$, particle diffusion $(D)$ and incidences of collision of particles in suspension by sedimentation $\left(I_{\mathrm{S}}\right)$ and by diffusion $\left(I_{\mathrm{D}}\right)$ were calculated. Calculations were related to average volume and urinary transit time of renal collecting ducts (CD) and of renal pelvis. $v_{\mathrm{S}}$ was in urine $0.026 \pm 0.012$, in UMS $0.022 \pm 0.01$ and in control $0.091 \pm 0.02 \mathrm{~cm} \mathrm{~min}^{-1}$ (mean $\pm \mathrm{SD}$ ). For urine, a $D$ of $9.53 \pm 0.97 \mu \mathrm{m}$ within $1 \mathrm{~min}$ can be calculated. At maximal crystal concentration, $I_{\mathrm{S}}$ was only 0.12 and $I_{\mathrm{D}}$ was $0.48 \mathrm{~min}^{-1} \mathrm{~cm}^{-3}$ which, even at an unrealistic permanent and maximal crystalluria, would only correspond to less than one crystal collision/week/CD, whereas to the same tubular wall being in horizontal position $1.3 \mathrm{crystals} / \mathrm{min}$ and to a renal stone 624 crystals $/ \mathrm{cm}^{2}$ min could drop by sedimentation. Sedimentation to renal tubular or pelvic wall, where crystals can accumulate and meet with a tissue calcification or a stone, is probably essential for stone formation. Since $v_{\mathrm{S}}$ mainly depends on particle size, reducing urinary supersaturation and crystal growth by dietary oxalate restriction seems to be an important measure to prevent aggregation.
\end{abstract}

J. M. Baumann $(\bowtie) \cdot$ B. Affolter $\cdot$ R. Meyer

Stone Research Center Viollier, Biel, Switzerland

e-mail: johannes.denise.baumann@bluewin.ch
Keywords Calcium oxalate $\cdot$ Sedimentation $\cdot$ Diffusion . Collision · Aggregation

\section{Introduction}

Nephrolithiasis can start from sub-micron particles of organic material complexed with amorphous hydroxyapatite, which after erosion to the papillary surface provide a platform to which crystals formed in the urine can attach [1]. Much work was done to elucidate this initial phase of nephrolithiasis [2,3]. However, for the transformation of kidney calcifications to a clinically symptomatic stone, further crystal apposition is necessary. It probably occurs during crystalluria by crystal aggregation (AGN) [4, 5]. Crystallization processes involved in stone formation are, apart from urinary supersaturation, essentially influenced by crystallization inhibitors like citrate and urinary macromolecules (UM), the latter comprising a large group of proteins and some glycosaminoglycans [6]. Physical chemistry has much contributed to a better understanding of stone disease [7]. Whereas nucleation and growth of crystals follow relative simple physico-chemical rules, AGN is more difficult to describe. In order to aggregate, particles have to collide with each other and then to be united by Van der Waals forces, viscous binding or, as recently shown, by the formation of solid calcium (Ca) bridges [8]. In suspensions not being stirred or shaken, particle collision can still occur by thermal diffusion or during sedimentation of particles with different sedimentation rates. Sedimentation or diffusion to walls of renal tubules or pelvis where crystals are retained by fluid drag [9] or attached to the tissue [2] is another mechanism enhancing particle collision. An equation describing AGN exclusively based on diffusion and with an unlimited size of aggregates has been developed by 
Smoluchowski [10]. However, in urine where AGN is inhibited by UM, aggregates are limited to a few crystals [11]. Sedimentation at rates increasing with particle size was frequently determined as indicator for AGN $[12,13]$ but its role in a first step of crystal AGN has been neglected. The aim of this study was to evaluate the importance of the different mechanisms of crystal collision and to show how they could be influenced by stone metaphylaxis. Sedimentation rate $\left(v_{\mathrm{S}}\right)$ of calcium oxalate was measured in urine and the corresponding UM solutions (UMS) where crystals were produced directly and AGN was found to be extremely rare owing to a high inhibitory activity. Thermal diffusion, which cannot easily be observed, was calculated after measurement of fluid viscosity and crystal dimensions, both being responsible for particle friction during sedimentation and diffusion. From these parameters and $v_{\mathrm{S}}$ the incidence of crystal collisions was calculated in suspension as well as on walls of renal collecting ducts, where stone formation may start by the retention of big aggregates [3] and in the renal pelvis, where stones grow to an obstructing size.

\section{Materials and methods}

Spot urine of seven healthy men of the staff with no previous history of stones was collected in the morning after high fluid intake on free diet, divided into three portions and, without further treatment, immediately was used for the isolation of UM, crystallization tests and viscosimetry.

\section{Preparation of UMS}

$55 \mathrm{~cm}^{3}$ of urine were injected into the dialysis fluid compartment of a capillary hemodialyser (Hemoflow F3, Fresenius AG, Bad Homburg, Germany), the exclusion limit of the dialysis membrane being $5 \mathrm{kDa}$. The compartment was closed and the urine dialysed against $12 \mathrm{~L}$ $\left(200 \mathrm{~cm}^{3} / \mathrm{min}\right)$ of deionized water [14].

\section{Crystallization tests and scanning microscopy}

UMS or distilled water (control) was buffered by $5 \mathrm{mM}$ sodium cacodylate to $\mathrm{pH} 6.0$ and $1.5 \mathrm{mM} \mathrm{Ca}$ was added from a solution of $1 \mathrm{M} \mathrm{CaCl}_{2}$. Ca oxalate crystals were produced by oxalate titration. Therefore, a quartz macro cuvette containing $2 \mathrm{~cm}^{3}$ of sample was placed into a thermostable cell holder of a Perkin Elmer spectrophotometer 550S (Perkin Elmer, Rotkreuz, Switzerland) at $37^{\circ} \mathrm{C}$. Under continuous stirring $0.05 \mathrm{mM} / \mathrm{min}$ sodium oxalate was added up to a final addition of $1.0 \mathrm{mM}$. Crystals were produced by the same procedure in urine after adjusting $\mathrm{pH}$ to 6.0. At the end of oxalate titration stirring was stopped and optical density (OD) was measured at $620 \mathrm{~nm}$ wavelength. Sedimentation of particles was studied following the decrease of OD. From the maximal OD reached by titration (mOD), the maximal OD decrease per minute observed during sedimentation $(d \mathrm{OD} /$ $d t$ ) and the height of the light beam or the length of the sedimentation path, respectively $(L=0.7 \mathrm{~cm})$, a maximal sedimentation rate $\left(v_{\mathrm{S}}, \mathrm{cm} / \mathrm{min}\right)$ was calculated from duplicate readings for each proband [12].

$v_{\mathrm{S}}=L(d \mathrm{OD} / d t) / \mathrm{mOD}$

Mean $v_{\mathrm{S}}$ was calculated from individual $v_{\mathrm{S}}$ and not from mean $d \mathrm{OD} / d t$ and mean mOD because these parameters are interdependent.

After sedimentation, particles were resuspended and millipore filtered (pore size $0.45 \mu \mathrm{m}$ ). Crystals and aggregates retained on the filters were visualised by a LEO 430 scanning electron microscope.

\section{Viscosimetry}

Kinematic viscosities of urine, UMS and buffered distilled water (control) were determined in triplicate by an Ubbelohde Micro Viscosimeter (Schott-Geräte $\mathrm{GmbH}$, Mainz, Germany) at $37^{\circ} \mathrm{C}$. To get the dynamic viscosity $(\eta)$ used for the different calculations, results of viscosimetry were multiplied by the density of solutions at $37^{\circ} \mathrm{C}$ $\left(\rho_{\mathrm{SOL}}=0.994 \mathrm{~g} \mathrm{~cm}^{-3}\right)$ and expressed in $\mathrm{g} \mathrm{cm}^{-1} \mathrm{~min}^{-1}$.

\section{Calculations}

To facilitate calculations all constants were also indicated within brackets in units of $\mathrm{g}, \mathrm{cm}$ and $\mathrm{min}$.

Sedimentation rate $\left(v_{\mathrm{S}}\right)$

$v_{\mathrm{S}}\left(\mathrm{cm} \mathrm{min}{ }^{-1}\right)$ for the slow sedimentation of particles can be calculated using Stokes's equation which has to be modified for non-spherical particles by correcting a virtual radius $(r, \mathrm{~cm})$ by a factor $q$ valid for a rotational ellipsoid [15] that approximates the actual crystal shape.

$v_{\mathrm{S}}=2 r^{2}\left(\rho_{\mathrm{COM}}-\rho_{\mathrm{SOL}}\right) g / 9 \eta q$

$\rho_{\mathrm{COM}}$ density of calcium oxalate monohydrate $(\mathrm{COM})$ $\left(2.23 \mathrm{~g} \mathrm{~cm}^{-3}\right), g$ gravitation acceleration $=9.81 \mathrm{~m} \mathrm{~s}^{-2}$ $\left(3.53 \times 10^{6} \mathrm{~cm} \mathrm{~min}^{-2}\right), \quad \eta$ dynamic viscosity of the solution $\left(\mathrm{g} \mathrm{cm}^{-1} \mathrm{~min}^{-1}\right) . r$ was calculated from average crystal volume $\left(V, \mathrm{~cm}^{3}\right)$ derived from SEM pictures:

$r=(3 V / 4 \pi)^{1 / 3}$

\section{Diffusion}

Diffusion differs fundamentally from the unidirectional sedimentation, as it is due to a three-dimensional random 
process that can best be expressed by the root mean square displacement $(\delta, \mathrm{cm})$ of a particle subject to Brownian motion. The average distance covered by a particle within a given time $(t, \mathrm{~min})$ is obtained as [15]:

$\delta(t)=\left(k_{\mathrm{B}} T t / \pi r \eta q\right)^{1 / 2}$

$k_{\mathrm{B}}$ Boltzmann constant $=1.38 \times 10^{-23} \mathrm{~m}^{2} \mathrm{~kg} \mathrm{~s}^{-2} \mathrm{~K}^{-1}$ $\left(4.97 \times 10^{-13} \mathrm{~cm}^{2} \mathrm{~g} \mathrm{~min}^{-2} \mathrm{~K}^{-1}\right), T$ absolute temperature at $37^{\circ} \mathrm{C}(310 \mathrm{~K})$.

Incidence of collision in suspension by diffusion $\left(I_{\mathrm{D}}\right)$

$I_{\mathrm{D}}$ per time and volume of a suspension $\left(\min ^{-1} \mathrm{~cm}^{-3}\right)$ with a particle concentration $\left(C, \mathrm{~cm}^{-3}\right)$ was calculated by:

$I_{\mathrm{D}}=\left(8 k_{\mathrm{B}} T / 3 \eta q\right) C^{2}$

Incidence of collision in suspension by sedimentation $\left(I_{\mathrm{S}}\right)$

As sedimentation rate increases with the square of particle radius (Eq. 2), AGN can also occur in suspension when during sedimentation larger particles with $r_{\mathrm{L}}$ and $C_{\mathrm{L}}$ reach and hit smaller ones, with $r$ and $C$, which sink more slowly. The corresponding incidence of collision by sedimentation per time and volume of the suspension $\left(I_{\mathrm{S}}, \mathrm{min}^{-1} \mathrm{~cm}^{-3}\right)$ is:

$I_{\mathrm{S}}=\pi\left(r_{\mathrm{L}}+r\right)^{2}\left(r_{\mathrm{L}}^{2}-r^{2}\right)\left[2\left(\rho_{\mathrm{COM}}-\rho_{\mathrm{SOL}}\right) g / 9 \eta q\right] C_{\mathrm{L}} C$

Calculations of $I_{\mathrm{S}}$ were performed for varying ratio $r_{\mathrm{L}} / r$, an average $C$ of $10,000 \mathrm{~cm}^{-3}$ and a $\log \left(C_{\mathrm{L}} / C\right)$ given by the empirical expression $-1.7\left(r_{\mathrm{L}} / r-1\right)$. These parameters were derived from measurements of volume/particle-size ratios in urine of stone patients and controls [9].

Incidence of collision with fixed particle $\left(I_{\mathrm{F}}\right)$

Furthermore, free moving crystals can collide with crystals being fixed on a tubular wall. Provided that $r$ is identical for all crystals, the radius of the tubular wall $(R)$ is much larger than $r$ and fluid drag near the tubular wall is accounted for by a parabolic velocity profile $[9,15]$, the incidence of such collisions per unit time $\left(I_{\mathrm{F}}, \mathrm{min}^{-1}\right)$ can be estimated by:

$I_{\mathrm{F}}=(1 / 2) \pi(2 r)^{2} L C t_{T}^{-1}(3 / 2)\left[1-(R-2 r)^{2} / R^{2}\right]$

$L$ length of tubule, $t_{\mathrm{T}}$ urinary transit time.

Sedimentation on unit surface $(S)$

The number $S$ of particles deposited per unit time on a unit surface $\left(\min ^{-1} \mathrm{~cm}^{-2}\right)$ is given by:
$S=C v_{\mathrm{S}}$

Crystal accumulation by sedimentation in a horizontally positioned tubule $(A)$

When renal tubules are in a horizontal position and $t_{\mathrm{T}} v_{\mathrm{S}}$, as in our case, is much larger than the diameter $2 R$ practically all crystals will drop to the ground of the tubule and will there be accumulated due to fluid drag. Under these special conditions, and when neglecting friction or retention of crystals at the wall, crystal accumulation per time ( $A$, $\min ^{-1}$ ) can be expressed by:

$A=\pi R^{2} L C t_{\mathrm{T}}^{-1}\left\{1-(3 / 2)\left[1-(R-r)^{2} / R^{2}\right]\right\}$

All calculations were performed for the mean $r$ obtained by sedimentation experiments in urine $(1.13 \mu \mathrm{m})$ and, with the exception of calculations by Eq. 6, for a maximal crystal concentration during crystalluria of $24,000 \mathrm{~cm}^{-3}$ [16]. For renal collecting ducts an average $L$ of $2.7 \mathrm{~cm}, R$ of $25 \times 10^{-4} \mathrm{~cm}$ and $t_{\mathrm{T}}$ of $0.82 \mathrm{~min}$ were used [9]. For the renal pelvis an average volume of $7 \mathrm{~cm}^{3}$ and a $t_{\mathrm{T}}$ of $12 \mathrm{~min}$ were assumed [17]. Statistical analyses were performed by Student's $t$ test.

\section{Results}

Crystallization experiments, determination and calculation of $v_{\mathrm{S}}$

Crystallization tests in urine and UMS showed significantly different results than in buffered distilled water (control). By SEM this difference could be attributed to AGN. SEM of sediments obtained in urine or in UMS revealed predominantly non-aggregated crystals of COM with a uniform shape and average dimensions of $4 \times 1.5 \times 1 \mu \mathrm{m}$ (Fig. 1a, b), whereas in the control most of these crystals were aggregated to big clusters (Fig. 1c). From dimensions of single crystals a correcting factor $(q)$ of 1.14 for nonspherical particles could be derived [15].

Since OD mainly reflects particle concentration, mOD reached after oxalate titration was higher in urine and UMS than in the control $(p<0.001)$, where particle concentration was reduced by AGN (Fig. 2). In the control, the highly aggregated particles showed also significantly higher values for $d \mathrm{OD} / d t$ and for $v_{\mathrm{S}}(p<0.001)$. Slightly higher $d \mathrm{OD} / d t$ and $v_{\mathrm{S}}$ observed in urine than in UMS can be attributed to the additional endogenous oxalate, producing somewhat larger crystals. Viscosity was almost identical in urine $(0.432 \pm$ $0.005)$, in UMS $(0.426 \pm 0.002)$ and in the control $(0.426$ $\left.\pm 0.004 \mathrm{~g} \mathrm{~cm}^{-1} \mathrm{~min}^{-1}\right)$. Results are given as mean $\pm \mathrm{SD}$. 
Fig. 1 Scanning microscopy of calcium oxalate monohydrate produced by oxalate titration in urine (a), UMS (b) and control (c). Bars indicating $20 \mu \mathrm{m}$
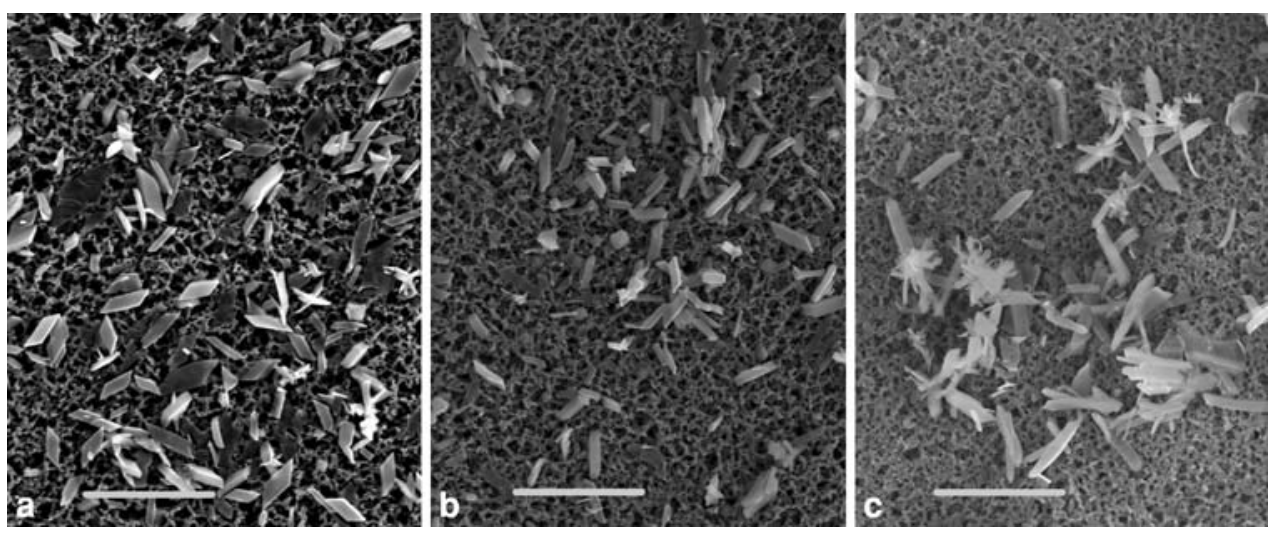

Fig. 2 Maximal optical density (mOD), maximal OD decrease $(d \mathrm{OD} / d t)$ and maximal sedimentation rate $\left(v_{\mathrm{S}}\right)$ in urine, UMS and control after oxalate titration. $\mathrm{mOD}, d \mathrm{OD} / d t$ and $v_{\mathrm{S}}$ values of urine and UMS are significantly different from those of the control $(p<0.001$, $n=14$ )
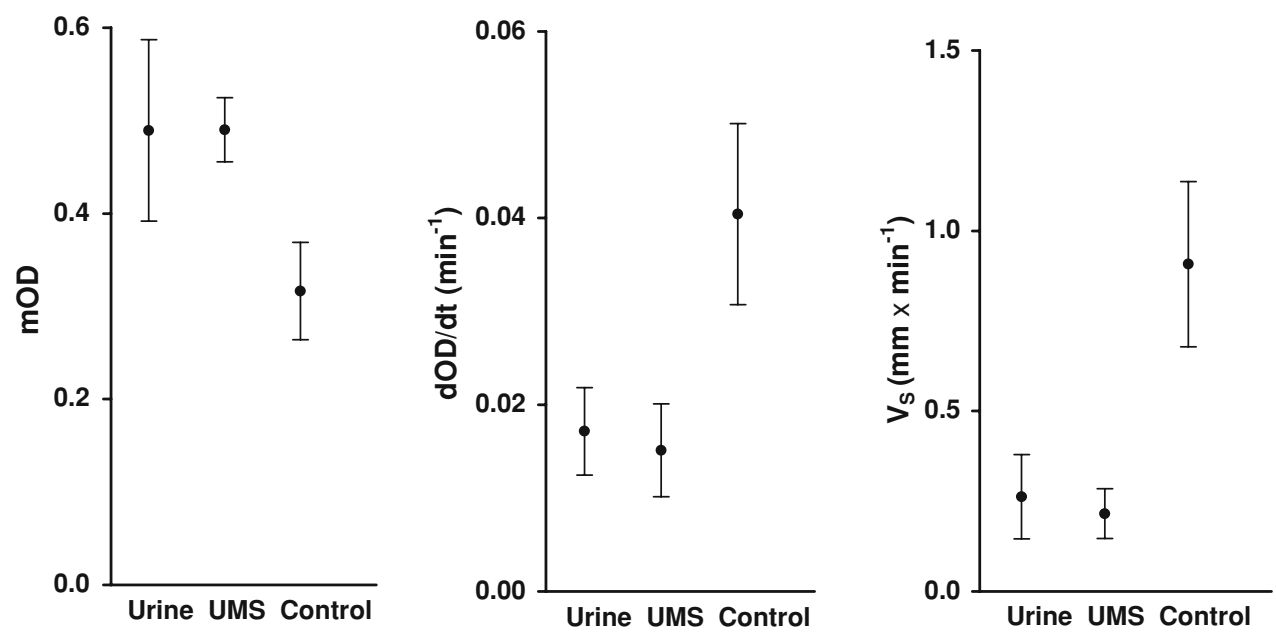

Calculation of $v_{\mathrm{S}}$ revealed with $0.025 \mathrm{~cm} / \mathrm{min}$ only a minimal difference to the experimental value of $0.026 \mathrm{~cm} / \mathrm{min}$.

\section{Calculation of crystal motion in suspension}

Distances which a particle might cover by sedimentation or by Brownian motion during different observed time periods are given in Table 1. Calculations were performed for current urinary transit times through kidney and renal pelvis and revealed an extremely slow diffusion of individual crystals.

\section{Calculation of crystal collision and accumulation}

The incidence of the collision of crystals in suspension by diffusion was very low. Even at the extreme crystal concentration $(C)$ of $24,000 \mathrm{~cm}^{-3} I_{\mathrm{D}}$ was only $0.48 \mathrm{~min}^{-1}$ $\mathrm{cm}^{-3}$. The incidence of collisions of free particles by sedimentation $\left(I_{\mathrm{S}}\right)$ was even lower than $I_{\mathrm{D}}$. A maximal $I_{\mathrm{S}}$ was found at an $r_{\mathrm{L}} / r$ ratio of 1.40 and had a value of only $0.12 \mathrm{~min}^{-1} \mathrm{~cm}^{-3}$ for a $C$ of $10,000 \mathrm{~cm}^{-3}$. Incidences of crystal collision indicated in Table 2 show that a collision between two free crystals in an average collecting duct can only be expected within several weeks. Also the chance that free floating particles reach a crystal being fixed on the tubular wall seems to be rather poor, since $I_{\mathrm{F}}$ was only $0.0016 \mathrm{~min}^{-1}$ corresponding to one collision every $10 \mathrm{~h}$.

However, sedimentation was found to be efficient especially for crystal accumulation (Table 2). For a $C$ of $24,000 \mathrm{~cm}^{-3}$ and a $v_{\mathrm{S}}$ of $0.026 \mathrm{~cm} \mathrm{~min}^{-1} S$ amounted to $624 \mathrm{~min}^{-1} \mathrm{~cm}^{-2}$. Within an average transit time of $12 \mathrm{~min}$ through a renal pelvis, this $S$ would correspond to the deposition of 7,500 crystals on $1 \mathrm{~cm}^{2}$ of a stone surface. For an identical crystalluria in a $\mathrm{CD}$ an accumulation rate $A$ of $1.35 \mathrm{~min}^{-1}$ was calculated, which means that at least one crystal per minute could be accumulated by sedimentation in a horizontally positioned collecting duct.

\section{Discussion}

For non-spherical particles like crystals, current physicochemical equations for sedimentation and diffusion have to be adapted by a dimension related correcting factor $(q)$ and by a volume related virtual radius $(r)$. Values for $q$ and $r$ are available for ellipsoid particles [15] but not for crystals. The parameters $q$ and $r$ determine together with $\eta$ particle 
Table 1 Motion of crystals by sedimentation and by diffusion in urine and UMS during average transit time in the kidney ( 3 min) and the renal pelvis (12 min) (calculated for crystals with $r=1.13 \mu \mathrm{m}$ and $q=1.14$, mean $\pm \mathrm{SD}, n=14$ )

\begin{tabular}{|c|c|c|c|c|}
\hline & \multicolumn{2}{|l|}{ Kidney after $3 \mathrm{~min}$} & \multicolumn{2}{|c|}{ Renal pelvis after $12 \mathrm{~min}$} \\
\hline & Sedimentation $(\mathrm{mm})$ & Diffusion (mm) & Sedimentation $(\mathrm{mm})$ & Diffusion $(\mathrm{mm})$ \\
\hline Urine & $0.79 \pm 0.35$ & $0.017 \pm 0.002$ & $3.15 \pm 1.40$ & $0.033 \pm 0.003$ \\
\hline UMS & $0.65 \pm 0.21$ & $0.017 \pm 0.001$ & $2.59 \pm 0.83$ & $0.035 \pm 0.002$ \\
\hline
\end{tabular}

Table 2 Incidence of crystal collision by diffusion at concentration $24,000 / \mathrm{cm}^{3}$ and by sedimentation at $10,000 / \mathrm{cm}^{3}$ in average collecting duct $\left(\mathrm{CD}\right.$, Volume $\left.=5.3 \times 10^{-5} \mathrm{~cm}^{3}\right)$ and renal pelvis $($ Volume $=7 \mathrm{~cm}^{3}$ ) and crystal accumulation by sedimentation at concentration $24,000 / \mathrm{cm}^{3}$ in $\mathrm{CD}$ being in horizontal position or on renal stone surface, as calculated for crystals with $r=1.13 \mu \mathrm{m}$ and $q=1.14$

\begin{tabular}{lll}
\hline & Collecting duct & Renal pelvis \\
\hline Collision & Collisions/min & Collisions/min \\
By diffusion & $2.5 \times 10^{-5}$ & 3.4 \\
By sedimentation & $6.7 \times 10^{-6}$ & 0.9 \\
Accumulation & Crystals/min in & Crystals/min on \\
& horizontal CD & $\mathrm{cm}^{2}$ stone surface \\
By sedimentation & 1.3 & 624 \\
\hline
\end{tabular}

friction in solutions $(f=6 \pi q r \eta)$, which also is not known for crystals. Therefore, the aim of our crystallization experiments was to demonstrate that modification of equations for sedimentation and diffusion derived for ellipsoids principally also can be applied for crystals. By slow oxalate titration we produced rhomboid crystals showing maximal deviation from spherical particles. Results of experimentally obtained $v_{\mathrm{S}}$ were then compared with those calculated from crystal volume and shape being aware that both methods imply some difficulties. Determining volumes from 2-dimensional pictures is problematic. Also sedimentation measurement poses several problems. Determining $v_{\mathrm{S}}$ is based on the extrapolation of the drop of OD being only in its initial part linear [12]. To avoid major turbidity due to flocculation of Tamm Horsfall glycoprotein (THG) or due to solid material other than the calcium oxalate crystals produced, we used freshly voided warm urine under a diuresis of at least $100 \mathrm{~cm}^{3} / \mathrm{h}$. Especially high ionic strength is known to provoke the polymerization of THG [18]. Slow oxalate titration was performed because it produces in UMS and urine crystal populations of a rather homogenous size and shape as observed in the control [14]. The minimal difference observed between calculated and experimentally determined $v_{\mathrm{S}}$ showed that $r$ and $q$ seem to be adequate to describe sedimentation and diffusion of crystals.

To be relevant for nephrolithiasis, results of crystallization tests and calculations have to be discussed in view of crystal concentrations actually found in urine, of renal anatomy and of urinary transit times through kidneys and the upper urinary tract. Total crystal concentrations are thought to vary during crystalluria between 7,200 and 24,000 crystals per $\mathrm{cm}^{3}$ [16]. Crystal size shows big variations and increases during renal passage by crystal growth in supersaturated urine $[16,19]$. The capacity of renal tubules is in the order of a few cubic micrometers [9] and that of a renal pelvis in the order of several cubic centimeters [17]. But tubular dimensions vary between the different nephrons [9, 16]. Urinary transit times in the kidney are 2-4 min [9] and in the renal pelvis on average 12 min depending on diuresis [17]. Near tubular walls the passage of small crystals may be delayed up to more than $1 \mathrm{~h}$ by special hydro-dynamic factors like fluid drag or sticking to the wall [9]. Being aware of all these anatomical and physiological complexities, for the calculations we used maximal crystal concentrations and average renal tubular and pelvic parameters found in current literature. Crystal friction and adhesion to tubular wall being difficult to quantify were neglected. Despite of all limitations and simplifications the following conclusions may be drawn from our study. The extremely low values of $I_{\mathrm{D}}$ and $I_{\mathrm{S}}$ demonstrate that AGN of free particles can hardly occur in the renal tubular system. Big aggregates observed in urine of some stone patients [19] may rather originate from the renal pelvis or the bladder, when crystals collide on a pelvic or bladder wall after sedimentation during a prolonged urinary residence time. As our calculations of crystal accumulation by sedimentation show, a similar but less extensive mechanism can be operative in renal tubules. Crystals, already formed in proximal tubules after high oxalate ingestion $[9,16]$, may undergo sedimentation to tubular walls being in horizontal position, where they may meet other crystals whose passage is delayed by fluid drag or adhesion to renal tissue. The latter mechanism may explain large aggregates found in CD near papillary surface [3]. During crystalluria, crystal collisions after sedimentation on tubular or pelvic walls seem to be more likely than in free solution.

It may look tentative to draw conclusions from our calculations on stone frequencies being on average only 1 stone/7 years. However, severe crystalluria occurs only occasionally and crystal deposits may be pushed out with urine flow or overgrowth by the tubular epithelial cells with 
subsequent removal by macrophages [20]. Furthermore, as shown again in this study, UM like THG are potent inhibitors and essentially influence AGN of $\mathrm{Ca}$ oxalate [21]. Their effect was especially pronounced in our study since the experimental conditions allowed the use of urine without previous removal of THG by centrifugation or filtration [22]. Therefore, on our SEM pictures aggregates hardly could be found in urine and UMS despite of intensive crystal collisions promoted by stirring during oxalate titration. UM are known to coat crystals [23] and thus to reduce crystal surfaces disposable for the apposition of other crystals [8]. This high inhibitory effect of UM may explain the fact that incidence of nephrolithiasis is much lower than could be expected from the widespread occurrence of crystalluria and kidney calcifications [6]. It also may explain the slow growth that is often observed for stone residues after ESWL as well as for kidney stones. Several groups have shown that urine of some stone formers is less capable of inhibiting crystal aggregation and that its ability to inhibit crystal aggregation decreases in direct proportion to the frequency of stone recurrence $[12,24]$.

Our equations show that crystal concentration $(C)$ and sedimentation rate $\left(v_{\mathrm{S}}\right)$, the latter being a function of crystal size or the virtual crystal radius $(r)$, respectively, are the most important factors which influence crystal collision by sedimentation. Provided that sedimentation and AGN are important for stone disease, dietary oxalate restriction and an increased fluid intake, both reducing urinary supersaturation and crystal growth, seem to be essential for stone metaphylaxis. Also the consumption of an acid load (a load of animal protein without high alkali consumption) is a risk for relative hyperoxaluria [25]. After a dietary oxalate load, the incidence of large urinary crystals and in stone patients also of aggregates markedly increased $[9,19]$. On the other hand, in renal collecting ducts and pelvis, $C$ and urinary transit time during which sedimentation can occur are reduced by an increased diuresis [16, 17]. Recent studies showed that the benefit of an increased urine volume largely seems to outweigh the concomitant loss of inhibition of AGN observed after UM dilution [14, 26].

\section{Conclusions}

Our experiments show that adaptations of equations for sedimentation and diffusion derived for ellipsoid particles also can be used for crystals. Calculations by these equations demonstrate, that crystal sedimentation, contrary to diffusion, seems to be most important for crystal collision being a first step of crystal AGN and thus for stone formation during crystalluria. Most collisions may occur in renal tubules where, if they are in horizontal position, crystals accumulate by sedimentation and in renal pelvis by crystal sedimentation on pre-existing stones. The chance for the formation of free aggregates in the renal tubular system seems to be rather poor. Since sedimentation rate increases with crystal size in square, all measures reducing crystal formation and growth are most important to prevent AGN.

Acknowledgments This work was supported by Vinetum Foundation, Biel, Switzerland. Scanning microscopy was performed at the Division for SEM, Berne University of Applied Sciences, Burgdorf, Switzerland.

Open Access This article is distributed under the terms of the Creative Commons Attribution Noncommercial License which permits any noncommercial use, distribution, and reproduction in any medium, provided the original author(s) and source are credited.

\section{References}

1. Matlaga BR, Coe FL, Evan AP, Lingeman JE (2007) The role of Randall's plaques in the pathogenesis of calcium stones. J Urol 177(1):31-38

2. Khan SR (1995) Calcium oxalate crystal interaction with renal tubular epithelium, mechanism of crystal adhesion and its impact on stone development. Urol Res 23:71-79

3. Khan SR, Thamilselvan S (2000) Nephrolithiasis: a consequence of renal epithelial cell exposure to oxalate and calcium oxalate crystals. Mol Urol 4(4):305-312

4. Baumann JM, Affolter B, Caprez U, Henze U (2003) Calcium oxalate aggregation in whole urine, new aspects of calcium stone formation and metaphylaxis. Eur Urol 43:421-425

5. Saw NK, Rao PN, Kavanagh JP (2008) A nidus, crystalluria and aggregation: key ingredients for stone enlargement. Urol Res 36(1):11-15

6. Khan SR, Kok DJ (2004) Modulators of urinary stone formation. Front Biosci 9:1450-1482

7. Finlayson B (1978) Physicochemical aspects of urolithiasis. Kidney Int 13:344-360

8. Baumann JM, Affolter B, Caprez U, Clivaz C, von Arx U (2009) The role of calcium for the aggregation of particles coated by urinary macromolecules. Urol Int 82:459-463

9. Robertson WG (2004) Kidney models of calcium oxalate stone formation. Nephron Physiol 98:21-30

10. Nielsen AE, Christoffersen J (1982) The mechanisms of crystal growth and dissolution. In: Konferenzen D, Nancollas GH (eds) Biological mineralization and demineralization. Springer, Berlin, pp 37-77

11. Baumann JM, Affolter B, Caprez U, Lauper D, Maier F, Siegrist HP, Zysset T (2000) Nucleation and aggregation of calcium oxalate in whole urine; spectrophotometric sedimentation analysis: a new approach to the study the aggregation of calcium oxalate dihydrate. Urol Res 28:147-154

12. Hess B, Nakagawa Y, Coe FL (1989) Inhibition of calcium oxalate monohydrate crystal aggregation by urine proteins. Am J Physiol 257:99-106

13. Christmas KG, Gower LB, Khan SR, El-Shall H (2002) Aggregation and dispersion characteristics of calcium oxalate monohydrate: effect of urinary species. J Colloid Interface Sci 256:168-174

14. Baumann JM, Affolter B, Caprez U, Clivaz C, Glück Z, Weber R (2007) Stabilization of calcium oxalate suspension by urinary 
macromolecules, probably an efficient protection from stone formation. Urol Int 79:267-272

15. Tinoco I Jr, Sauer K, Wang JC (1985) Physical chemistryprinciples and applications in biological sciences, 2nd edn. Prentice-Hall, Inc., Englewood Cliffs, 07632

16. Kok DJ, Khan SR (1994) Calcium oxalate nephrolithiasis, a free or fixed particle disease. Kidney Int 46:847-854

17. Finlayson B, Reid F (1978) The expectation of free and fixed particles in urinary stone disease. Invest Urol 15:442-448

18. Scurr DS, Robertson WG (1986) Modifiers of calcium oxalate crystallization found in urine. III. Studies on the role of TammHorsfall mucoprotein and of ionic strength. J Urol 136(2):505507

19. Robertson WG, Peacock M, Nordin BEC (1969) Calcium crystalluria in recurrent renal stone formers. Lancet 2:21-24

20. de Water R, Noordermeer C, Houtsmuller AB, Nigg AL, Stijnen T, Schröder FH, Kok DJ (2000) Role of macrophages in nephrolithiasis in rats: an analysis of the renal interstitium. Am J Kidney Dis 36(3):615-625

21. Grover PK, Ryall RL, Marshall VR (1990) Does Tamm-Horsfall mucoprotein inhibit or promote calcium oxalate crystallization in human urine? Clin Chim Acta 190(3):223-238
22. Ryall RL, Grover PK, Thurgood LA, Chauvet MC, Fleming DE, van Bronswijk W (2007) The importance of a clean face: the effect of different washing procedures on the association of Tamm-Horsfall glycoprotein and other urinary proteins with calcium oxalate crystals. Urol Res 35(1):1-14 (epub 2007 Feb 3)

23. Khan SR, Finlayson B, Hacket RL (1983) Stone matrix as proteins adsorbed on crystal surfaces: a microscopic study. Scan Electron Microsc 1:379-384

24. Kok DJ, Papapoulos SE, Bijvoet OL (1990) Crystal agglomeration is a major element in calcium oxalate urinary stone formation. Kidney Int 37(1):51-56

25. Kok DJ, Iestra JA, Doorenbos CJ, Papapoulos SE (1990) The effects of dietary excesses in animal protein and sodium on the composition and the crystallization kinetics of calcium oxalate monohydrate in urines of healthy men. J Clin Endocrinol Metab 71:861-867

26. Guerra A, Allegri F, Meschi T, Adorni G, Prati B, Nouvenne A, Novarini A, Maggiore U, Fiaccadori E, Borghi L (2005) Effects of urine dilution on quantity, size and aggregation of calcium oxalate crystals induced in vitro by an oxalate load. Clin Chem Lab Med 43(6):585-589 